\title{
Preferred Surgical and Anesthesia Techniques for Cataract Surgery in Jordan
}

\author{
Wedad Al-dolat (iD \\ Noor M Alqudah $\mathbb{D}^{2}$ \\ Dema Atoum' \\ Rami Al-Omari (1D) \\ Moawiah Khatatbeh (D) $^{3}$ \\ 'Department of Ophthalmology, Faculty \\ of Medicine, Yarmouk University, Irbid, \\ Jordan; ${ }^{2}$ Department of Ophthalmology, \\ Faculty of Medicine, Jordan University of \\ Science and Technology, Irbid, Jordan; \\ ${ }^{3}$ Department of Basic Medical Sciences, \\ Faculty of Medicine, Yarmouk University, \\ Irbid, Jordan
}

Purpose: To study the current practices in Jordan regarding cataract surgical procedures and anesthesia trends for cataract surgery.

Methods: A cross-sectional survey of members of the Jordanian Ophthalmology Society was conducted in October 2020. The questionnaire included questions about participants' demographics, the preferred surgical techniques for cataracts, the preferred anesthesia technique for cataract surgery, the factors which affect the choice of anesthesia technique, the use of sedation, who gives the anesthesia, if there is an anesthesia-trained person who observes the patient during cataract surgery, and the changing trends towards anesthesia between the surgeons.

Results: More than half of the respondents $(59.1 \%)$ had been in practice for more than 5 years. The preferred method for routine cataract was phacoemulsification for most participants $(98.4 \%)$. For mature cataract, phacoemulsification was the preferred method for $61.4 \%$ of participants. More than half $(55.1 \%)$ used topical with intracameral anesthesia for phacoemulsification. Two thirds of the participants (66.3\%) performed retrobulbar anesthesia for extracapsular cataract surgery. In the majority of cases $(86.6 \%)$, the respondent themself is the one who administers the anesthesia. No sedation was used before surgery in $62.6 \%$ of cases. Two thirds of the respondents $(70.1 \%)$ reported that they had an anesthesia-trained person monitoring the patient during surgery. Patient cooperation was the most important factor $(70.9 \%)$ affecting the surgeon's choice of anesthesia technique followed by surgeon skill and experience (57.5\%).

Conclusion: Presently, phacoemulsification is the preferred surgical technique for cataract in Jordan. Topical with intracameral anesthesia is the most common anesthesia for phacoemulsification while retrobulbar anesthesia is the most common for extracapsular cataract extraction.

Keywords: cataract, anesthesia, phacoemulsification, cross-sectional, Jordan

\section{Introduction}

Cataract, which is the opacification of the lens, is one of the commonest causes of vision loss worldwide. ${ }^{1}$ The proportion of blindness because of cataract ranges from 12.7\% in North America to $42.0 \%$ in Southeast Asia. ${ }^{1}$ The most common leading cause of blindness globally in 2020 in those aged 50 years and older was cataract. ${ }^{2}$ In a study conducted by Al-Zubi et al, the prevalence of cataract in Jordan was $37.8 \%$ among study participants. ${ }^{3}$ Results from another study in Northern Jordan demonstrated that $46.7 \%$ of blindness usually occurs due to untreated cataract. ${ }^{4}$

Surgery is still the only effective treatment option, which gives a very good sight outcome. Cataract surgery is the most frequently performed eye operation
Correspondence: Wedad Al-dolat

Department of Ophthalmology, Faculty of Medicine, Yarmouk University, Irbid, Jordan

Tel +962772393968

Email wedad.dolat@yu.edu.jo 
worldwide. ${ }^{5}$ Fascinating advancements in cataract surgical techniques and its safety profile make cataract surgery one of the most successful treatments in medicine. ${ }^{5}$ Cataract surgery has a long history and has advanced very quickly in the past decades. ${ }^{5,6}$ Generally, there are several basic surgical types, including phacoemulsification, extracapsular cataract extraction (ECCE), and manual small-incision cataract surgery (MSICS). ${ }^{7}$

As for all surgical procedures, anesthesia is an important part of cataract surgery. There have been major changes in the provision of cataract surgery; accordingly, anesthesia in cataract surgery has evolved over the last two decades. ${ }^{8,9}$ The inevitable changes in the delivery of anesthesia have progressed from general anesthesia to local anesthesia, ie retrobulbar, peribulbar, and sub-tenon to topical anesthesia. An acceptable anesthesia modality should ensure patient comfort during and post-surgery. Generally, the choice of anesthesia modality must be assessed on an individual patient and surgeon basis. ${ }^{10}$ Globally, there is an apparent growing trend towards the use of topical anesthesia. ${ }^{11}$

Preferences in cataract surgery and anesthesia practices vary in different countries. However, there is paucity of data on the current practice of cataract surgery and anesthesia in Jordan. The aim of this survey is to identify the current practices in Jordan regarding cataract surgical procedures and anesthesia trends. The understanding of current practices is important because of the rapidly changing nature of cataract surgery. Hopefully, this understanding will establish a baseline for areas of improvement.

\section{Methodology}

A cross-sectional survey was conducted in October 2020 among the members of the Jordanian Ophthalmology Society (JOS). A structured questionnaire was developed by two researchers after reviewing the available literature and was composed of 15 questions. Then the content validity of the questionnaire was tested by two independent ophthalmologists. The questionnaire was computerized using Google Forms and distributed to participants via email. To ensure its reliability, the questionnaire was pilot-tested with the first 15 responses; based on these responses and the feedback, Cronbach's alpha score was 0.86 . An invitation to participate in the study was sent via email to the members of JOS. Participation was voluntary and participants who were interested in filling out the survey questionnaire have provided written informed consent electronically. The questionnaire included questions about participants' demographics, the preferred surgical techniques for cataracts, the preferred anesthesia technique for cataract surgery, the factors which affect the choice of anesthesia technique, the use of sedation before surgery, who administers the anesthesia, if there is an anesthesiatrained person who observes the patient during cataract surgery, and the changing trends towards anesthesia between the surgeons.

The questionnaire was anonymous, to maintain the privacy and confidentiality of all information collected in the study. Also, the participants' responses were kept blinded until all participants had completed the questionnaire. Data were entered into a spreadsheet. Statistical analysis was performed using the Statistical Program for Social Sciences (IBM SPSS Corp, SPSS Statistics ver. 25 , USA).

The study was conducted according to the Helsinki Declaration principles and was approved by the Institutional Review Board of the Jordan University of Science and Technology.

\section{Results}

\section{Participants' Demographics}

A total of 127 ophthalmologists responded and completed the questionnaire, representing a response rate of $84.6 \%$. The mean age of the participants was 39.68 years; $72.4 \%$ were male, and $51.9 \%$ had more than 5 years of surgical experience. Of the respondents, $42.5 \%$ worked at Royal Medical Services hospitals. The demographics of the participants are shown in Table 1.

\section{Cataract Surgery Technique}

For routine cataract, almost all participants (98.4\%) used phacoemulsification. Only two ophthalmologists used ECCE for routine cataract. For mature cataract, phacoemulsification was the preferred technique for 78 (61.4\%) ophthalmologists, and ECCE was the preferred technique for $48(37.8 \%)$ ophthalmologists in the sample. Only one ophthalmologist responded with scleral tunnel. Thus, in all but the academic sector, respondents are split almost halfway between phacoemulsification and ECCE for mature/ dense cataract (Figure 1). Yet, the ones who chose ECCE were on average younger than those who chose phacoemulsification, and more likely to have finished their ophthalmology training less than 10 years ago (Figure 2).

Combining routine and mature/dense cataract, phacoemulsification is the preferred surgical technique in $79.9 \%$ 
Table I Demographics of the Participants

\begin{tabular}{|l|l|l|}
\hline & Number & Percent \\
\hline Gender & 35 & \\
Female & 92 & 27.6 \\
Male & 39.68 & 72.4 \\
\hline Age (mean, SD) & & 8.897 \\
\hline Institution & 14 & \\
Ministry of Health & 54 & 11.0 \\
Royal Medical Services & 40 & 42.5 \\
Private sector & 19 & 31.5 \\
Academic/university sector & & 15.0 \\
\hline How long ago training was completed & 52 & \\
0-5 years & 27 & 40.9 \\
$6-10$ years & 20 & 21.3 \\
II-15 years & 17 & 15.7 \\
I6-20 years & 6 & 13.4 \\
2I-25 years & 0 & 4.7 \\
$26-30$ years & 4 & 0 \\
$31-35$ years & 1 & 3.1 \\
$36-40$ years & 0.8 \\
\hline
\end{tabular}

of cataract surgeries, whereas ECCE is the preferred technique in $19.7 \%$ of surgeries.

\section{Anesthesia for Cataract Surgery}

More than half $(55.1 \%)$ of the respondents used topical with intracameral anesthesia for phacoemulsification. This leaves a cumulative $44.9 \%$ for the three types of regional anesthesia (retrobulbar, peribulbar, sub-tenon) combined together (Figure 3).

Of the respondents, $66.3 \%$ used retrobulbar anesthesia for ECCE procedure. A total of 92.1\% (117 out of 127) used regional anesthetic for ECCE (Figure 4).

Patient cooperation, surgeon skill and experience, procedure safety and the type of procedure were the top four factors affecting the surgeon's choice of anesthesia technique (Figure 5).

Regarding giving sedation before the surgery, $62.6 \%$ did not give sedation before cataract surgery, while $26.6 \%$ sometimes used benzodiazepines for their patients. In the majority of cases (110 out of 127), the respondent themself is the one who administers the anesthesia; $70.1 \%$ of the respondents said that they had an anesthesia-trained person monitoring the patient during surgery.

The questionnaire contained two questions about the changing trends among surgeons towards anesthesia technique. Twenty-four respondents $(18.9 \%)$ reported that they have changed their anesthesia technique in the last 6 months. Of those, $17(70.8 \%)$ used topical anesthesia for phacoemulsification, but $17(70.8 \%)$ still use retrobulbar anesthesia for ECCE. Thirty-five $(27.6 \%)$ of the respondents said they are considering changing their anesthesia technique. Of those, 19 (54.3\%) used retrobulbar anesthesia for phacoemulsification, and $26(74.3 \%)$ used retrobulbar anesthesia for ECCE.

\section{Discussion}

This survey provides an overview of the current practices of JOS members performing cataract surgery. Of the 127 participants, 75 (59.1\%) had been in surgical practice for more than 5 years. There were some variations in preferences between surgeons regarding the surgery technique and the anesthesia used for cataract surgery.

Almost all respondents (98.4\%) used phacoemulsification for routine cataract. Also, phacoemulsification was the preferred procedure for mature cataract for more than half of the participants $(61.4 \%)$. This is similar to what was found by a survey in Singapore, where all participants used phacoemulsification for routine cataract and almost half $(46 \%)$ used phacoemulsification for mature cataract. ${ }^{12}$ Furthermore, our results are comparable to the data from Korea and Japan where the preferred method for cataract surgery was phacoemulsification in $95 \%$ and $94 \%$ of the respondents, respectively. ${ }^{13,14}$ These results indicate that the primary eye care services provided in Jordan are of a high standard, similar to the standards followed in developed countries. Moreover, the preference of surgeons for phacoemulsification reflects the good training and technology.

For mature cataract, 37.8\% used ECCE. However, those who chose ECCE for mature cataract were more likely to be young ophthalmologists who had finished their training less than 10 years ago. This is the opposite to the results from Singapore where surgeons who had completed ophthalmology training 15 years ago or more were much more likely to use ECCE for mature cataract than those who had completed training less than 15 years ago. $^{12}$ Our results can be explained by the fact that young ophthalmologists prefer ECCE for mature cataract because of their low exposure to this type of cataract and so they have a lack of experience in doing phacoemulsification for mature cataract.

Regarding the anesthesia for cataract surgery, for phacoemulsification, more than half of the respondents $(55.1 \%)$ used topical with intracameral anesthesia, 


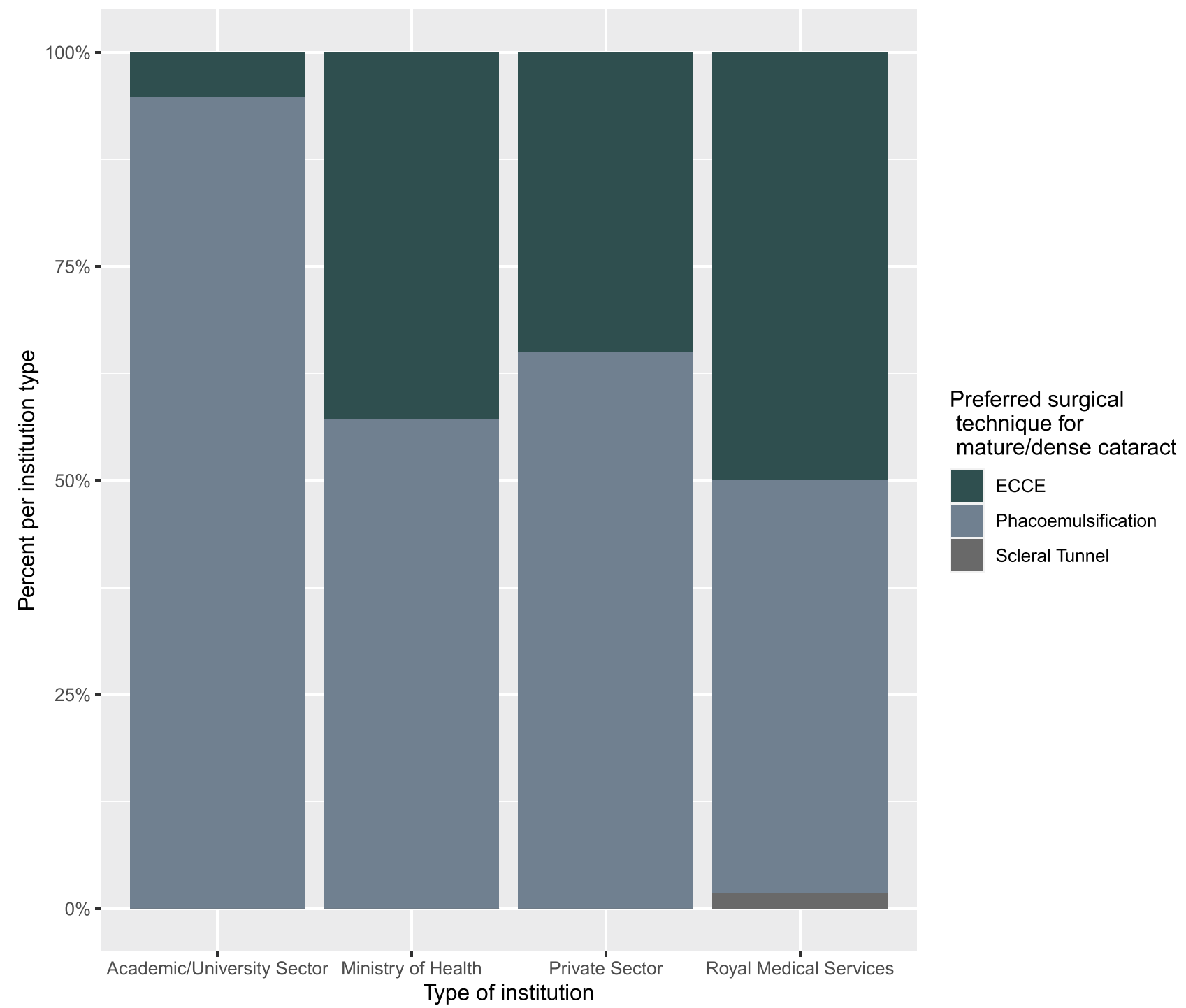

Figure I Preferred surgical technique for mature/dense cataract according to the type of institution.

followed by retrobulbar anesthesia (28.3\%). Anesthesia preferences for routine cataract surgery vary across the world. In some countries like Japan, New Zealand and the UK, sub-tenon anesthesia is the most popular technique, ${ }^{14-16}$ while topical anesthesia is the anesthesia of choice in Singapore, Korea, the USA, Canada and Malaysia. ${ }^{12,13,17-19}$ In Nigeria, peribulbar is the most common anesthesia technique for cataract surgery $(49.1 \%)$ and retrobulbar is the second most common $(37.9 \%) .{ }^{20}$ In our results, retrobulbar anesthesia was the second most common technique used for phacoemulsification $(28.3 \%)$. In a global survey of cataract practices it was found that topical anesthesia is the preferred technique among participants in more than $90 \%$ of routine cases. ${ }^{21}$ The popularity of topical anesthesia is increasing, because it is believed that the analgesia provided by topical anesthesia is adequate for small-incision cataract surgery. ${ }^{22}$ In addition to that, topical anesthesia is a safe, needleless procedure, free from sight-threatening complications. ${ }^{23}$ Therefore, the acceptance of topical anesthesia for cataract surgery is high from both the patient's and surgeon's perspective. ${ }^{23}$ Our results regarding the anesthesia used for cataract surgery are similar to the trend worldwide; again, this indicates that the standards of care provided in Jordan are comparable to international standards.

For ECCE, the preferred anesthesia was retrobulbar (66.1\%), followed by peribulbar (17.3\%). In Singapore, peribulbar anesthesia (79\%) was the preferred method for ECCE. ${ }^{12}$ This reflects the complexity of mature cataract where ECCE is used and the need to have more control of 


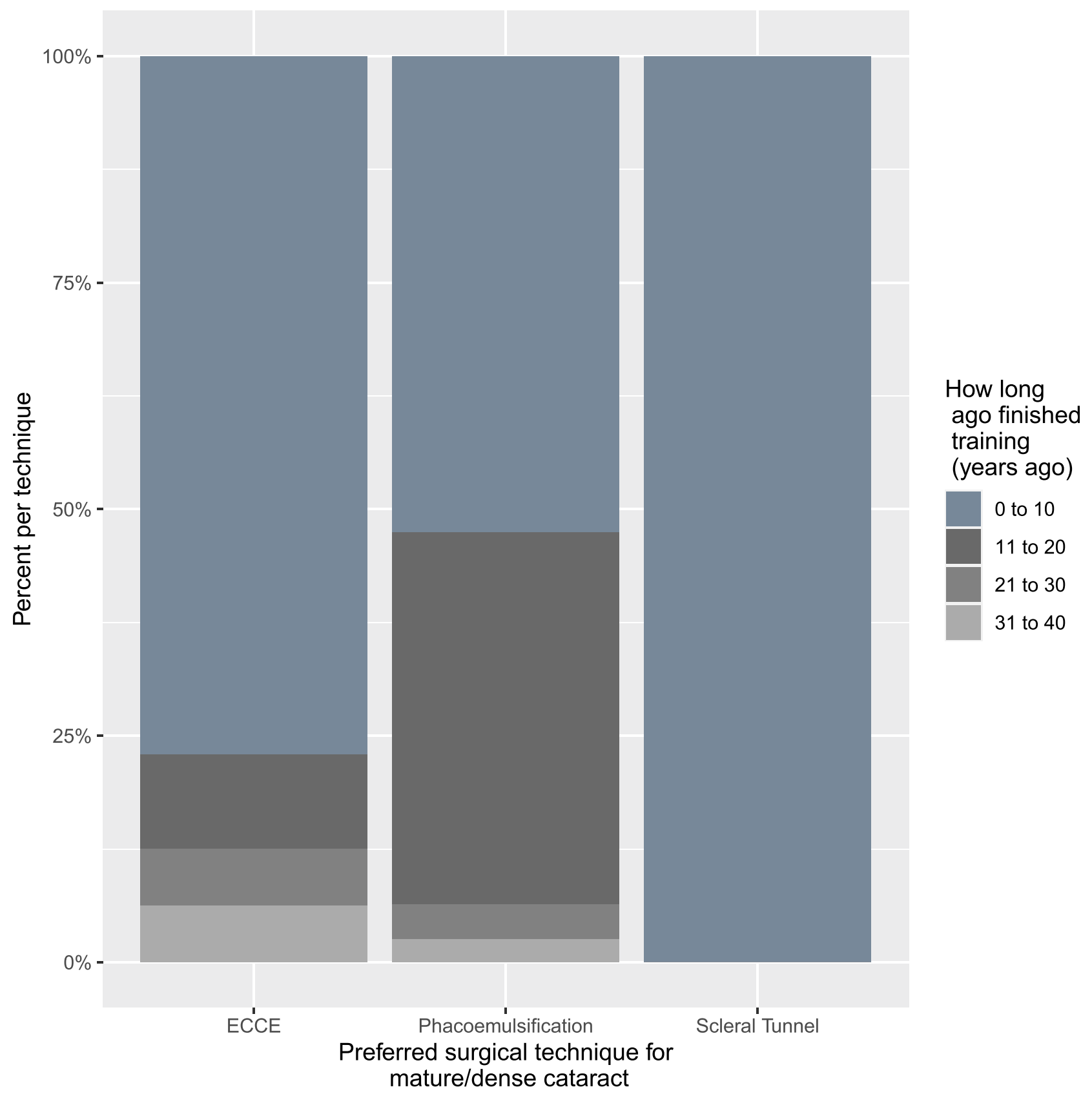

Figure 2 Preferred surgical technique for mature/dense cataract according to how long ago finished training.

eye movements and pain, and so the use of regional anesthesia.

In the questionnaire, we asked about the reasons behind the surgeon's choice for a specific technique of anesthesia. In a multiple choice question where participants could choose more than one answer, patient cooperation $(70.9 \%)$, surgeon skill and experience $(57.5 \%)$, procedure safety $(49.6 \%)$ and the type of procedure $(40.9 \%)$ were the top four factors affecting the surgeon's choice of anesthesia technique.
Concerning the use of sedation before cataract surgery, most respondents did not use sedation. This might reflect that patient cooperation is the most influencing factor for the type of anesthesia and, because of this, no sedation is needed prior to the surgery. Information from a UK database shows that mild sedation is used in only $1.4 \%$ of cataract operations under local anesthesia. ${ }^{16}$ Also, in the global survey by Rossi et al, it was found that $69 \%$ of the respondents used no sedation in $90 \%$ of cases. ${ }^{21}$ In the majority of cases $(86.6 \%)$, the surgeon themself 


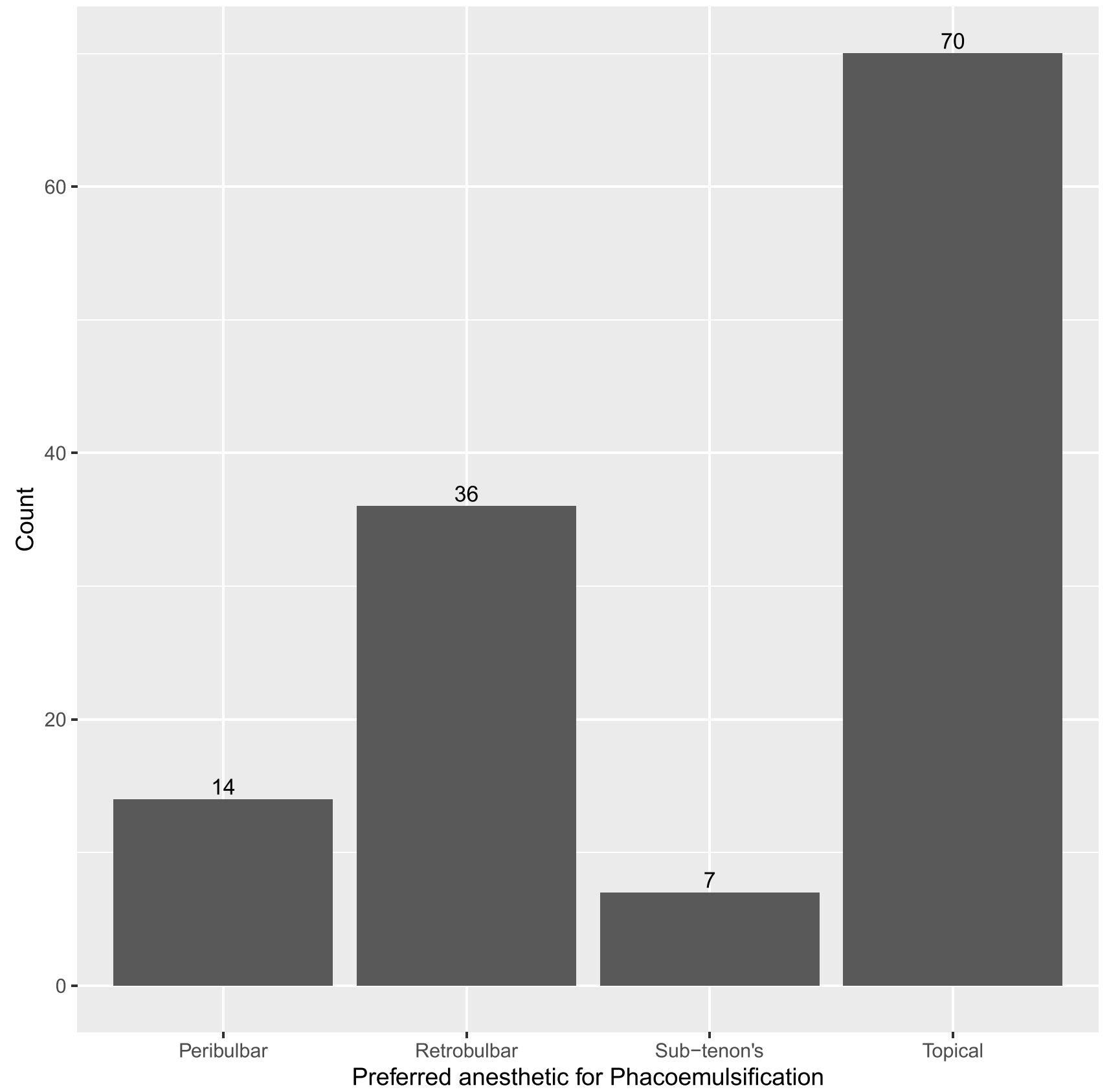

Figure 3 Preferred anesthesia for phacoemulsification.

administers the anesthesia. Our practice in this issue is similar to the available data from other countries like Singapore and the UK. ${ }^{12,16}$ Most of the respondents (70.1\%) said that they have an anesthesia-trained person who monitors the patient during surgery. There is a need for monitoring because most cataract patients tend to be elderly with the presence of other comorbidities. This is comparable to the results of a study that included surgeons from several countries attending the 2002 Congress of the International Council of Ophthalmology, in which most participants $(74 \%)$ responded that an anesthesia-trained person monitored the vast majority of patients during cataract surgery. ${ }^{24}$

Nearly one fourth of the respondents said they have changed their anesthesia technique in the last 6 months; among those, two thirds of them used topical anesthesia for phacoemulsification and two thirds used retrobulbar for ECCE. Nearly a third of the respondents were considering changing their anesthesia technique; half of those used retrobulbar anesthesia for phacoemulsification 


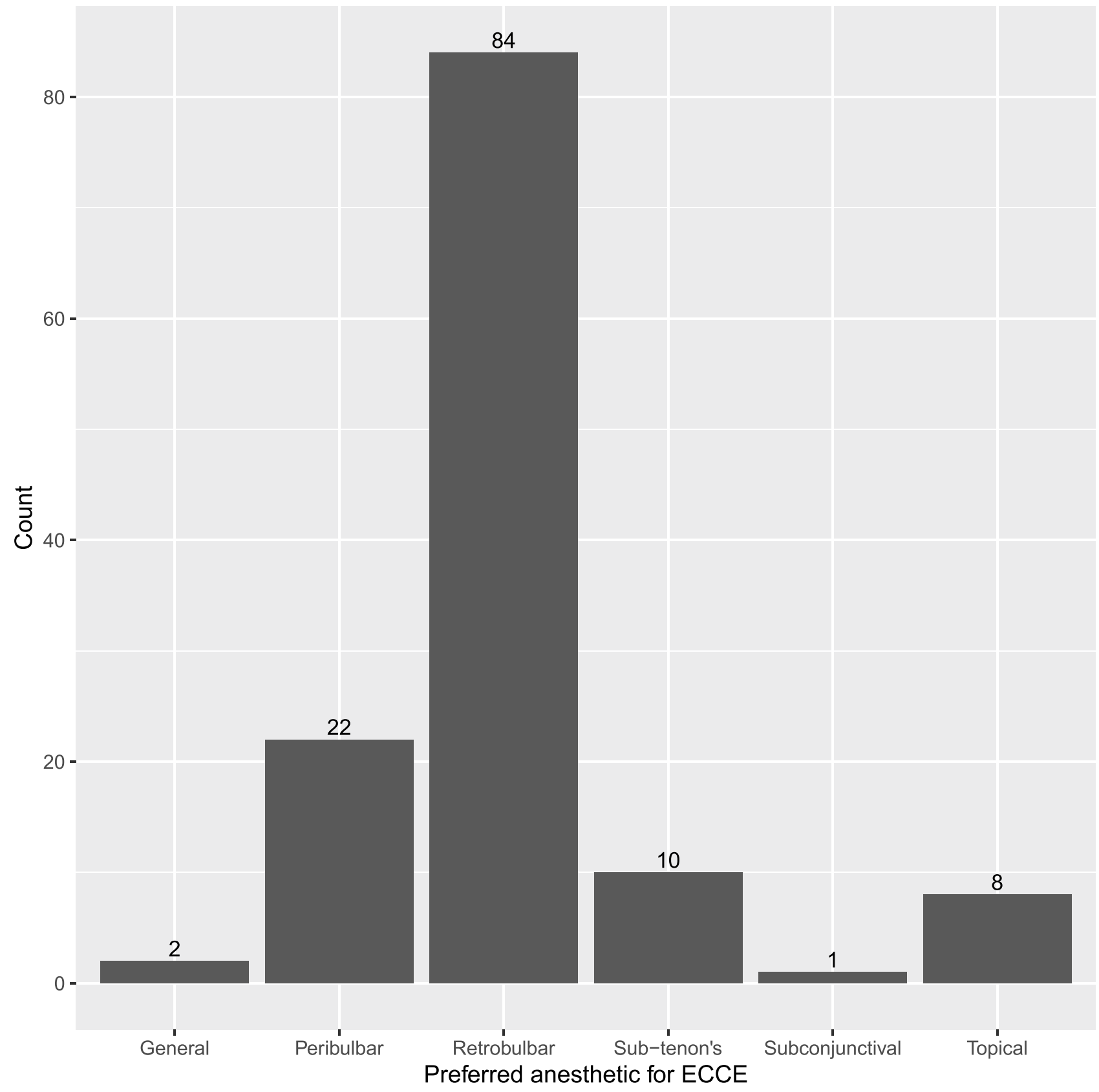

Figure 4 Preferred anesthesia for ECCE.

and three quarters used retrobulbar anesthesia for ECCE. These results might reflect the trend of changing towards a less invasive technique for cataract surgery anesthesia, as is the situation worldwide. ${ }^{23}$

To the best of our knowledge, this is the first study describing the current practice of cataract surgery and anesthesia in Jordan. The authors think that one of the limitations of this study is the relatively small sample size. Also, it was not possible to take into account the preferences of ophthalmologists who did not respond or ophthalmology trainees who have yet to qualify as members of JOS.

\section{Conclusion}

This study provides an overview of the present cataract surgery practices of JOS members. In Jordan, phacoemulsification under topical with intracameral anesthesia was the procedure of choice for routine cataract. For mature 


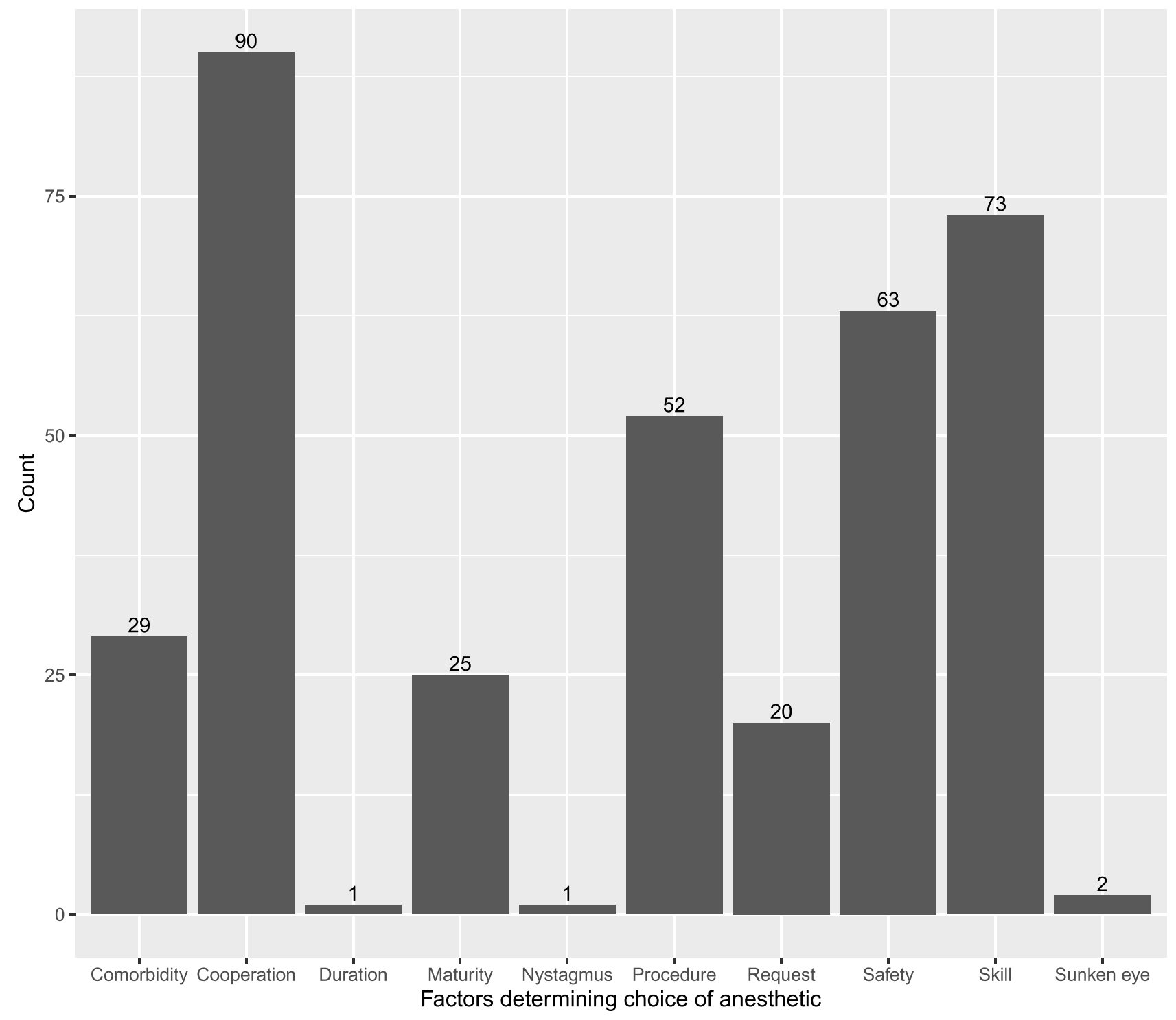

Figure 5 Facors determining choice of anesthetic.

cataract, phacoemulsification was also the technique of choice for most participants, under retrobulbar anesthesia.

\section{Data Sharing Statement}

All data are available upon request.

\section{Disclosure}

The authors report no funding or conflicts of interest for this work.

\section{References}

1. Lee CM, Afshari NA. The global state of cataract blindness. Curr Opin Ophthalmol. 2017;28(1):98-103. doi:10.1097/ICU.00000000 00000340
2. GBD 2019 Blindness and Vision Impairment Collaborators; Vision Loss Expert Group of the Global Burden of Disease Study. Causes of blindness and vision impairment in 2020 and trends over 30 years, and prevalence of avoidable blindness in relation to VISION 2020: the Right to Sight: an analysis for the Global Burden of Disease Study [published correction appears in Lancet Glob Health. 2021 Apr;9(4):e408]. Lancet Glob Health. 2021;9(2):e144-e160. doi:10.1016/S2214-109X(20)30489-7

3. Al-Zubi K, Hijazeen M, Nasser R. Quality of life after cataract surgery in Jordan. Glob J Health Sci. 2018;10(7):128.

4. Rabiu MM, Al Bdour MD, Abu Ameerh MA, Jadoon MZ. Prevalence of blindness and diabetic retinopathy in northern Jordan. Eur J Ophthalmol. 2015;25(4):320-327. doi:10.5301/ejo.5000557

5. Davis G. The evolution of cataract surgery. Mo Med. 2016;113 (1):58-62.

6. Menapace R. Developments in modern cataract surgery-a critical overview. Ther Umsch. 2016;73(2):53-59.

7. Lin ZN, Chen J, Zhang Q, et al. The 100 most influential papers about cataract surgery: a bibliometric analysis. Int $J$ Ophthalmol. 2017;10(10):1586-1591. doi:10.18240/ijo.2017.10.17 
8. Athanasiov P, Henderson T. Ocular anaesthesia and the never-ending story. Br J Ophthalmol. 2010;94:1.

9. Ali-Melkkila T, Virkkila M, Leino K, Palve H. Regional anaesthesia for cataract surgery: comparison of three techniques. $\mathrm{Br}$ J Ophthalmol. 1993;77:771-773.

10. Shah R. Anesthesia for cataract surgery: recent trends. Oman J Ophthalmol. 2010;3(3):107-108. doi:10.4103/0974-620X.71881

11. Naor J, Slomovic AR. Anesthesia modalities for cataract surgery. Curr Opin Ophthalmol. 2000;11(1):7-11. doi:10.1097/00055735200002000-00003

12. Tam YS, Kumar CM, Au Eong KG, Yip CC, Cheng J. Trends in cataract surgery technique and anaesthesia preferences in Singapore: a 2016 survey. Ann Acad Med Singap. 2018;47(9):390-393.

13. Chung JK, Lee HK, Kim MK, et al. Cataract surgery practices in the Republic Of Korea: a survey of the Korean Society of cataract and refractive surgery 2018. Korean J Ophthalmol. 2019;33(5):451-457. doi:10.3341/kjo.2019.0064

14. Oshika T, Amano S, Araie M, Majima Y, Leaming DV. Current trends in cataract and refractive surgery in Japan: 1999 survey. Jpn $J$ Ophthalmol. 2001;45(4):383-387. doi:10.1016/s0021-5155(01) 00333-1

15. Pick ZS, Leaming DV, Elder MJ. The fourth New Zealand cataract and refractive surgery survey: 2007. Clin Exp Ophthalmol. 2008;36 (7):604-619. doi:10.1111/j.1442-9071.2008.01869.x

16. El-Hindy N, Johnston RL, Jaycock P, et al. The cataract national dataset electronic multi-centre audit of 55,567 operations: anaesthetic techniques and complications. Eye (Lond). 2009;23(1):50-55. doi:10.1038/sj.eye.6703031
17. Leaming DV. Practice styles and preferences of ASCRS members2003 survey. J Cataract Refract Surg. 2004;30(4):892-900. doi:10.1016/j.jcrs.2004.02.064

18. Ong-Tone L. Practice patterns of Canadian Ophthalmological Society members in cataract surgery-2016 survey. Can J Ophthalmol. 2017;52(1):2. doi:10.1016/j.jcjo.2016.11.022

19. Thevi T, Godinho MA. Trends and complications of local anaesthesia in cataract surgery: an 8-year analysis of 12992 patients. $\mathrm{Br}$ $J$ Ophthalmol. 2016;100(12):1708-1713. doi:10.1136/bjophthalmol2015-307785

20. Adekoya BJ, Onakoya AO, Balogun BG, Oworu O. Current practice of ophthalmic anesthesia in Nigeria. Middle East Afr J Ophthalmol. 2013;20(4):341-344. doi:10.4103/0974-9233.120022

21. Rossi T, Romano MR, Iannetta D, et al. Cataract surgery practice patterns worldwide: a survey. BMJ Open Ophthalmol. 2021;6: e000464. doi:10.1136/bmjophth-2020-000464

22. Claoué C, Lanigan C. Topical anaesthesia for cataract surgery. Aust N Z J Ophthalmol. 1997;25(4):265-268. doi:10.1111/j.14429071.1997.tb01513.x

23. Mönestam E, Kuusik M, Wachtmeister L. Topical anesthesia for cataract surgery: a population-based perspective. J Cataract Refract Surg. 2001;27(3):445-451. doi:10.1016/s0886-3350(00)00637-4

24. Eichel R, Goldberg I. Anaesthesia techniques for cataract surgery: a survey of delegates to the Congress of the International Council of Ophthalmology, 2002. Clin Exp Ophthalmol. 2005;33(5):469-472. doi:10.1111/j.1442-9071.2005.01063.x
Clinical Ophthalmology

\section{Publish your work in this journal}

Clinical Ophthalmology is an international, peer-reviewed journal covering all subspecialties within ophthalmology. Key topics include: Optometry; Visual science; Pharmacology and drug therapy in eye diseases; Basic Sciences; Primary and Secondary eye care; Patient Safety and Quality of Care Improvements. This journal is indexed on PubMed

\section{Dovepress}

Central and CAS, and is the official journal of The Society of Clinical Ophthalmology (SCO). The manuscript management system is completely online and includes a very quick and fair peer-review system, which is all easy to use. Visit http://www.dovepress.com/ testimonials.php to read real quotes from published authors. 